\title{
Erectile Dysfunction and Premature Ejaculation Drugs: Mode of Action and Analytical Methods Literature Review
}

\author{
Adel E Ibrahim ${ }^{1}$, Magda Elhenawee ${ }^{2}$, Hanaa Saleh ${ }^{2}$, and Mahmoud M Sebaiy,* \\ ${ }^{1}$ Department of Pharmaceutical Analytical Chemistry, Faculty of Pharmacy, Port Said University, Egypt \\ ${ }^{2}$ Department of Analytical Chemistry, Faculty of Pharmacy, Zagazig University, Zagazig, Egypt \\ ${ }^{3}$ Department of Medicinal Chemistry, Faculty of Pharmacy, Zagazig University, Zagazig, Egypt
}

*Corresponding author: Mahmoud M Sebaiy, Department of Medicinal Chemistry, Faculty of Pharmacy, Zagazig University, Zagazig, 44519, Egypt, Tel: 01062780060; Fax: 0552303266; E-mail: mmsebaiy@zu.edu.eg; sebaiym@gmail.com

Received: 27 Mar, 2021 | Accepted: 15 Jul, 2021 | Published: 22 Jul, 2021

Citation: Ibrahim AE, Elhenawee M, Saleh H, Sebaiy MM (2021) Erectile Dysfunction and Premature Ejaculation Drugs: Mode of Action and Analytical Methods Literature Review. J Drug Res Dev 7(1): dx.doi.org/10.16966/2470-1009.163

Copyright: (C) $2021 \mathrm{lbrahim} \mathrm{AE,} \mathrm{et} \mathrm{al.} \mathrm{This} \mathrm{is} \mathrm{an} \mathrm{open-access} \mathrm{article} \mathrm{distributed} \mathrm{under} \mathrm{the} \mathrm{terms} \mathrm{of} \mathrm{the} \mathrm{Creative} \mathrm{Commons} \mathrm{Attribution} \mathrm{License,}$ which permits unrestricted use, distribution, and reproduction in any medium, provided the original author and source are credited.

\section{Abstract \\ Introduction to Erectile Dysfunction and Premature Ejaculation}

This literature review focuses on drugs used for erectile dysfunction and premature ejaculation, in respect of mode of action and different analytical techniques used for their determination either alone or in combination with other drugs in different pharmaceutical and biological matrices. The cited drugs are Sildenafil, Avanafil, Apomormphine, Yohimbine, Tramadol, Dapoxetine, and Trazodone.

Keywords: Literature review; Erectile dysfunction; Premature ejaculation; Mode of action; Analytical techniques
Among all male sexual disorders, erectile dysfunction and premature ejaculation are the most prevalent. Erectile Dysfunction (ED) mainly affects elder men, however, Premature Ejaculation (PE) affects men at all age groups.

ED is defined as the inability of achieve or even maintain erection sufficient enough to produce satisfactory sexual performance. $40 \%$ of men aging between 40 and 70 years old are susceptible to ED [1]. ED can originate from psychological causes (e.g. stress, depression, anxiety, etc.) or organic causes (e.g. Diabetes, cardiovascular diseases, hypogonadism, etc.) [2]. According to study delivered by the Massachusetts Male Aging, complete impotence was observed in $39 \%$ of men having heart diseases, $28 \%$ of diabetics and $15 \%$ of hypertensive patients [3]. Management of ED depends on identifying the causative factor; however, about $80 \%$ of men diagnosed with ED have organic disease [4]. The diagnosis of ED and assessment of treatment outcomes are challenging jobs to physicians, since patients are often silent or reluctant to discuss this sensitive issue. Oral and sublingual drugs are the most commonly used dosage forms in management of ED.

PE can be defined as the fast ejaculation which occurs soon after sexual intercourse was initiated. PE is independent of age and is commonly associated with feelings of frustration or distress [4]. The underlying cause of PE is not completely known. However; several neurotransmitters have been identified in the complex ejaculation process of which serotonin exhibited an inhibitory effect on ejaculation $[5,6]$.
ED and PE have been known to co-occur in $30 \%$ of patients [7]. Their diagnosis can be an obstacle facing physicians when they try to differentiate between them. Difficulties in maintaining erection after early ejaculation in absence of ED problem can be misdiagnosed as ED condition. So, complete assessment of sexual function should be carried out in order to differentiate between PE and ED.

\section{Sildenafil (SDN) as citrate $[2,8]$}

Molecular formula: $\mathrm{C}_{28} \mathrm{H}_{38} \mathrm{~N}_{6} \mathrm{O}_{11} \mathrm{~S}$.

Molecular weight: $666.7 \mathrm{~g} / \mathrm{mol}$.

IUPAC name: 5-[2-ethoxy-5-(4-methylpiperazin-1-yl) sulfonylphenyl]-1-methyl-3-propyl-4H-pyrazolo[4,3-d]pyrimidin7-one;2-hydroxypropane-1,2,3-tricarboxylic acid (Figure 1).

Physical properties: SDN as citrate is a white crystalline powder. It's very sparingly soluble in water. pKa values 6.0 and 7.3.

Mechanism of action: More than $90 \%$ of SDN dose is absorbed with nearly $40 \%$ reaching systemic circulation unchanged following first-pass metabolism. SDN inhibits Phosphodiesterase Type 5 Enzyme (PDE5) which is responsible for degradation of cGMP in the corpus cavernosum. Penile erection during sexual stimulation is caused by increased penile blood flow resulting from the relaxation of penile arteries and corpus cavernosal smooth muscle. This response is mediated by the release of Nitric Oxide (NO). NO stimulates the synthesis of cGMP in smooth muscle cells. Cyclic GMP causes smooth muscle relaxation and increased blood flow into the corpus cavernosum. The inhibition of Phosphodiesterase type 5 (PDE5) by sildenafil enhances erectile function by increasing the amount of cGMP. 

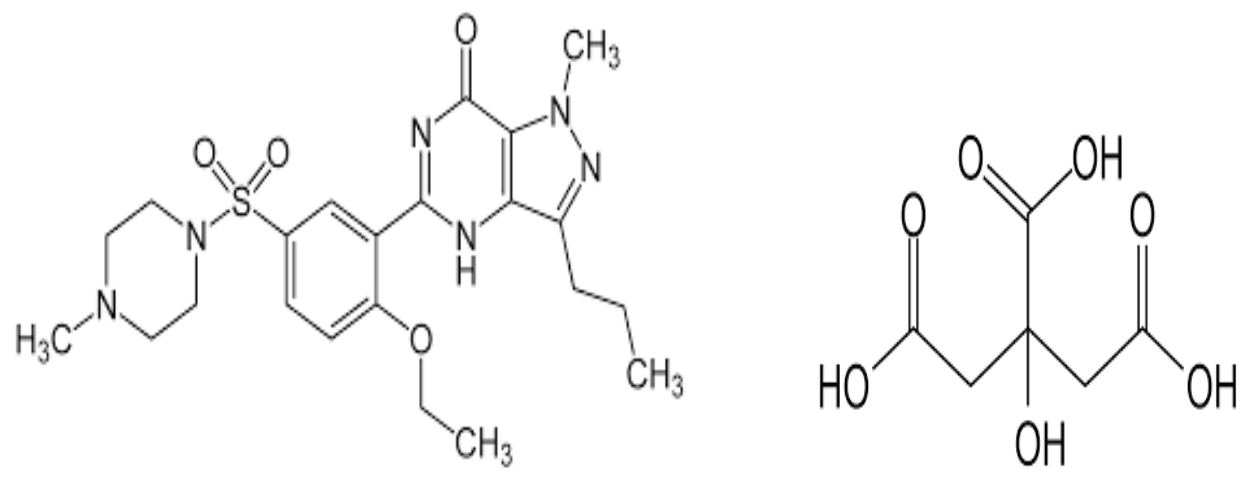

Figure 1: Sildenafil citrate chemical structure.

Literature review: Several methods were reported for determination of SDN. Spectrophotometric and spectrofluorimetric methods for determination of SDN in pharmaceutical dosage forms [9-11] were reported. The spectrophotometric methods required azo-dye formation or complexation with other chromophore before measuring the absorbances in the range 400-600 $\mathrm{nm}$. The spectrofluorimetric method used surfactant coated resin for preconcentration of the sample but gave higher sensitivity. LOD was $0.15 \mathrm{ng} / \mathrm{mL}$.

Other electrochemical methods [12-14] were reported. Chromatographic determination of SDN in different matrices including human plasma, breast milk and other biological fluids were reported also [15-18]. The GC-MS/MS method quantified SDN together with five of its analogues in dietary supplements using capillary columns in twelve minutes. The LC methods quantified SDN using reversed phase C18 columns and UV-detection and more sensitive by MS/MS detector.

Another method was reported using capillary electrophoresis coupled with MS/MS detection [19] which was more sensitive coupled with MS/MS detector. The LOD was $14 \mathrm{ng} / \mathrm{mL}$.

\section{Avanafil (AVN) [20,21]}

Molecular formula: $\mathrm{C}_{23} \mathrm{H}_{26} \mathrm{C}_{1} \mathrm{~N}_{7} \mathrm{O}_{3}$.

Molecular weight: $483.96 \mathrm{~g} / \mathrm{mol}$.

IUPAC name: 4-[(3-chloro-4-methoxyphenyl) methylamino]-2[(2S)-2-(hydroxymethyl) pyrrolidin-1-yl]-N-(pyrimidin-2-ylmethyl) pyrimidine-5-carboxamide (Figure 2 ).

Physical properties: AVN is white powder very sparingly soluble in water. It has pKa values of 5.5 and 12.5.

Mechanism of action: AVN is a newly FDA approved and ultrafast acting PDE-5 inhibitor. Rapidly absorbed and does not accumulate after multiple doses. $T_{\text {max }}=30-45$ minutes; Time to peak response $=10$ minutes. The inhibition of (PDE-5) by AVN enhances erectile function by increasing the amount of cGMP which is responsible for penile muscle relaxation and increased blood flow.

Literature review: Reviewing literature revealed very few papers reported for determination of AVN alone [22,23]. Chromatographic determination of AVN in combination with other drugs was reported with only DPX as described in table 1. Only one spectrophotometric method was reported for AVN/DPX mixture determination [24] at 247 and $211 \mathrm{~nm}$ using $0.1 \mathrm{M}$ hydrochloric acid as a solvent. The linearity ranges was between $2-12 \mu \mathrm{g} / \mathrm{mL}$ for both AVN and DPX.

\section{Apomormphine (APM) as hydrochloride $[2,8]$}

Molecular formula: $\mathrm{C}_{17} \mathrm{H}_{17} \mathrm{NO}_{2}$. $\mathrm{HCl}$.

Molecular weight: $312.8 \mathrm{~g} / \mathrm{mol}$.

IUPAC name: (6aR)-6-methyl-5,6,6a,7-tetrahydro-4H-dibenzo [de,g] quinoline-10,11-diol (as hydrochloride) (Figure 3).

Physical properties: APM as hydrochloride is yellow to grayish crystalline powder. It's sparingly soluble in water and it acquires green color upon exposure to air and light. It has pKa values of 6.6 and 13.3.

Mechanism of action: APM is amorphine derivative acting as a dopaminergic agonist. Its primary effect occurs in the hypothalamus. It was found that impotent patients have impairment of central dopaminergic functions [28]. The usual initial dose has been $2 \mathrm{mg}$ taken sublingually about 20 minutes before sexual activity. A dose of 3 $\mathrm{mg}$ was used on subsequent occasions if necessary with a minimum of 8 hours between doses.

Literature review: Determination of APM alone in dosage forms and human plasma has been reported by several methods including spectrophotometric [29], HPLC [30,31] and proton NMR spectroscopy [32].

Only two methods were reported for determination of APM in combination with other drugs (e.g. SDN, tadalafil,) used for ED as listed in table 2. No method was reported for APM determination with drugs used for PE.

\section{Yohimbine (YHB) as hydrochloride $[2,8]$}

Molecular formula: $\mathrm{C}_{21} \mathrm{H}_{26} \mathrm{~N}_{2} \mathrm{O}_{3}$. $\mathrm{HCl}$.

Molecular weight: $390.91 \mathrm{~g} / \mathrm{mol}$.

IUPAC name: methyl(1S,15R,18S,19R,20S)-18-hydroxy$1,3,11,12,14,15,16,17,18,19,20,21$-dodecahydroyohimban-19carboxylate(as hydrochloride) (Figure 4).

Physical properties: YHB as hydrochloride is white to slight yellow crystalline powder. It's sparingly soluble in water and insoluble in alcohol or dichloromethane. It acquires green color upon exposure to air and light. It has pKa values of 7.7 and 14.7.

Mechanism of action: YHB is a natural alkaloid that was reproduced synthetically because of its $\alpha 2$-adrenoceptor antagonist effect which was found to enhance ED with psychological origin [2]. Mechanism exerted by YHB for treatment of ED is still unknown. Two mechanisms are suggested. It may increase sympathetic effect by 
increasing nor-epinephrine release by its adrenergic blocking effect. Another suggested mechanism may involve other neurotransmitters such as dopamine and serotonin and cholinergic receptors.

Literature review: Determination of $\mathrm{YHB}$ in drug extracts, pharmaceutical products or biological fluids were reported extensively [35-38]. YHB determination with other drugs used for treatment of ED (PDE-5 inhibitors) was reported in only one method using HPLCMS/MS [39].

\section{Tramadol (TMD) as hydrochloride $[2,8]$}

Molecular formula: $\mathrm{C}_{16} \mathrm{H}_{25} \mathrm{NO}_{2}$. $\mathrm{HCl}$.

Molecular weight: $299.8 \mathrm{~g} / \mathrm{mol}$.

IUPAC name: methyl(1S,15R,18S,19R,20S)-18-hydroxy$1,3,11,12,14,15,16,17,18,19,20,21$-dodecahydroyohimban-19carboxylate(as hydrochloride) (Figure 5).

Physical properties: TMD is a white or almost white, crystalline powder. It's freely soluble in water and in methanol, very slightly soluble in acetone. It has $\mathrm{pKa}$ values of 9.2 and 13.1.

Mechanism of action: TMD is an opioid analgesic used for control of moderate to severe pain. TMD has noradrenergic and serotonergic effects. TMD has two enantiomers; the $(+)$ enantiomer has higher affinity for the OP3 receptor and preferentially inhibits serotonin uptake and enhances serotonin release. The (-) enantiomer preferentially inhibits norepinephrine reuptake by stimulating alpha2-<smiles>COc1ccc(CNc2nc(N3CCC[C@H]3CO)ncc2C(=O)NCc2ncccn2)cc1Cl</smiles>

Figure 2: Avanafil chemical structure.<smiles>CN1CCc2cccc3c2[C@@H]1Cc1ccc(O)c(O)c1-3</smiles>

Figure 3: Apomorphine Hydrochloride chemical structure. adrenergic receptors. TMD is misused in treatment of PE because of its inhibitory effect on serotonin reuptake. As mentioned earlier, serotonin exhibited an inhibitory effect on ejaculation.

Literature review: Several methods were reported for determination of TMD alone in dosage forms and different biological fluids. HPLC [40,41], GC [42], Spectrometry [43,44], and even by electrochemical methods $[45,46]$ were reported. Simultaneous determination of TMD with other analgesics was reported using LC [47-49].

\section{Dapoxetine (DPX) as hydrochloride [2,8]}

Molecular formula: $\mathrm{C}_{21} \mathrm{H}_{23} \mathrm{NO}$. $\mathrm{HCl}$.

Molecular weight: $341.88 \mathrm{~g} / \mathrm{mol}$.

IUPAC name: (1S)-N,N-dimethyl-3-naphthalen-1-yloxy-1phenylpropan-1-amine(as hydrochloride) (Figure 6).

Physical properties: DPX is a white or almost white crystalline powder. Its hydrochloride salt is freely soluble in water and in methanol. pKa value is 9.0.

Mechanism of action: DPX is a rapidly absorbed short-acting serotonin selective reuptake inhibitor (SSRI). It has a unique pharmacokinetic profile, with a fast absorption (time to maximum plasma concentration is about $1 \mathrm{~h}$ ) and rapid elimination (half-life of 1-2 h). Although it's not yet approved by FDA, it's approved globally by a number of countries (including European countries) as the first drug for on-demand treatment of PE.

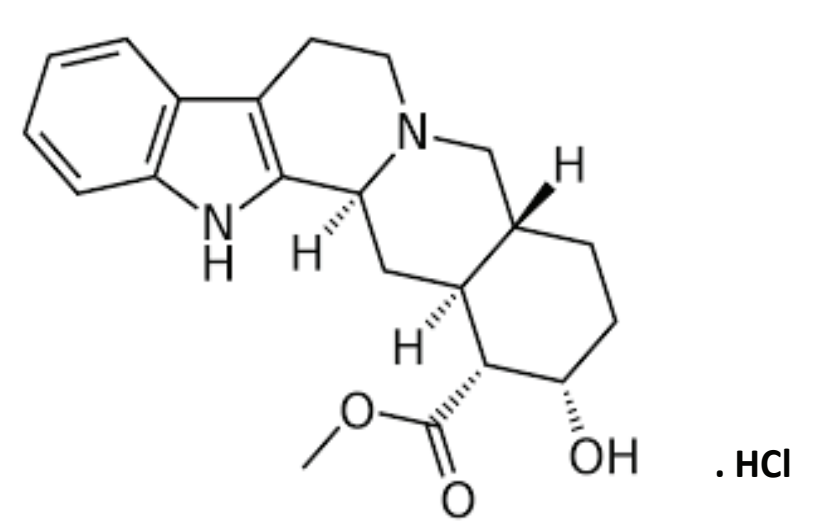

Figure 4: Yohimbine Hydrochloride chemical structure.

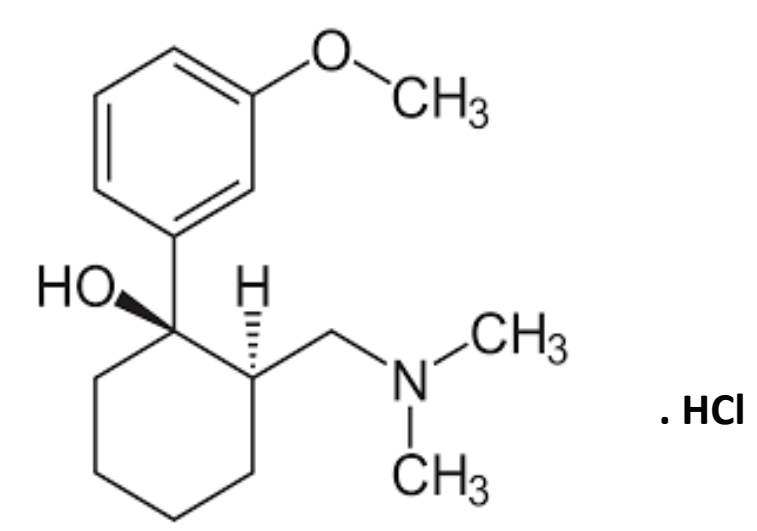

Figure 5: Tramadol Hydrochloride chemical structure. 
<smiles>CN(C)[C@H](CCOc1cccc2ccccc12)c1ccccc1</smiles>

Figure 6: Dapoxetine Hydrochloride chemical structure.

Table 1: Summary of reported chromatographic methods for AVN determination in combination with other drugs.

\begin{tabular}{|l|c|c|c|c|}
\hline \multicolumn{1}{|c|}{ Matrix } & Column & Mobile phase & System & Ref. No \\
\hline Tablets & $\begin{array}{c}\text { Silica gel } \\
\text { plate }\end{array}$ & $\begin{array}{c}\text { Toluene: } \\
\text { methanol(9:1) }\end{array}$ & HPTLC & {$[25]$} \\
\hline $\begin{array}{l}\text { Tablets \& } \\
\text { plasma }\end{array}$ & C18 & $\begin{array}{c}0.15 \% \text { triehylamine in } \\
\text { water: ACN (60:40) }\end{array}$ & $\begin{array}{c}\text { HPLC- } \\
\text { fluorescence }\end{array}$ & {$[26]$} \\
\hline Tablets & C18 & $\begin{array}{c}\text { ACN: Ammonium } \\
\text { acetate buffer } \\
\text { (gradiant) }\end{array}$ & HPLC-UV & [27] \\
\hline
\end{tabular}

Table 2: Summary of reported chromatographic methods for APM determination in combination with other drugs.

\begin{tabular}{|l|c|c|c|c|}
\hline \multicolumn{1}{|c|}{ Matrix } & Column & Mobile phase & System & Ref. No \\
\hline Tablets & Calixarene & $\begin{array}{c}\text { Sodium perchlorate } \\
\text { buffer: ACN (65: } 35)\end{array}$ & HPLC-UV & {$[33]$} \\
\hline Tablets & C18 & $\begin{array}{c}0.5 \% \text { formic acid in } \\
\text { water: ACN }\end{array}$ & $\begin{array}{c}\text { HPLC- MS/ } \\
\text { MS }\end{array}$ & {$[34]$} \\
\hline
\end{tabular}

DPX inhibits serotonin reuptake, hence serotonin level rises and exerts its inhibitory effect on ejaculation.

Literature review: DPX is a newly developed SSRI drug. Some papers were reported for its determination alone in pharmaceutical dosage forms and in biological fluids [51-53]. However, being the first approved drug for on-demand treatment of $\mathrm{PE}$, its determination with other drugs that are used for treatment of ED was reported. A summarized list of methods for determination of DPX with other drugs is detailed in table 3.

Trazodone (TZD) as hydrochloride $[2,8]$

Molecular formula: $\mathrm{C}_{19} \mathrm{H}_{22} \mathrm{C}_{1} \mathrm{~N}_{5} \mathrm{O} . \mathrm{HCl}$.

Molecular weight: $408.3 \mathrm{~g} / \mathrm{mol}$.

IUPAC name: 2-[3-[4-(3-chlorophenyl)piperazin-1-yl] propyl]-[1,2,4]triazolo[4,3-a]pyridin-3-one(as hydrochloride) (Figure 7).

Physical properties: TZD is a white or almost white crystalline powder. Its hydrochloride salt is sparingly soluble in water and in chloroform. It's practically insoluble in ether. It has pKa value of 7.1.
Mechanism of action: TZD is a tricyclic antidepressant acting as Serotonin Selective Reuptake Inhibitor (SSRI). It has an antagonist effect at 5-HT receptors.

TZD has no effect on the central reuptake of dopamine, it does not appear to have very significant anti-muscarinic properties, but it has a marked sedative action.

TZD is a unique drug that is abused in treatment of ED and PE. Its serotonin reuptake inhibitor effect cause delay in ejaculation. It also causes a condition known as priapism which is a condition in which a penis remains erect for hours in the absence of stimulation or after stimulation has ended so it was also tried for treatment of ED [64]. Another added value for TZD was reported as it's capable of increasing sexual libido in both men and women $[65,66]$.

Literature review: TZD was discovered earlier before, so several methods describing its determination in different matrices (pharmaceutical dosage forms, plasma, urine, etc.) were reported [6770]. Despite its known misuse in PE and ED conditions, no method was reported for determination of TZD with any other drugs treating these conditions.

Table 3: Summary of reported methods for DPX determination in combination with other drugs for ED.

\begin{tabular}{|l|c|c|c|}
\hline \multicolumn{1}{|c|}{ Matrix } & Drugs & Method & Ref. No \\
\hline Tablets & Vardenafil- DPX & Spectrophotometry & {$[54]$} \\
\hline Tablets & Vardenafil- DPX & Thermal analysis & {$[55]$} \\
\hline Tablets & Vardenafil- DPX & Spectroscopy / HPLC & {$[56]$} \\
\hline Tablets & Tadalafil- DPX & HPLC-UV & {$[57]$} \\
\hline Tablets & Tadalafil- DPX & HPLC-UV & {$[58]$} \\
\hline Tablets and \\
human plasma & Tadalafil- DPX & HPLC-fluorescent & {$[59]$} \\
\hline Tablets & Sildenafil- DPX & Spectrophotometry & {$[60]$} \\
\hline Tablets & Sildenafil- DPX & HPTLC & {$[61]$} \\
\hline Tablets & Sildenafil- DPX & HPLC-UV & {$[62]$} \\
\hline Tablets & Sildenafil- DPX & HPLC-UV & {$[63]$} \\
\hline
\end{tabular}<smiles>O=c1n(CCCN2CCN(c3cccc(Cl)c3)CC2)nc2ccccn12</smiles>

Figure 7: Trazodone Hydrochloride chemical structure. 


\section{Conclusion}

This literature review is introducing brief summary about drugs used for erectile dysfunction and premature ejaculation specifically Sildenafil, Avanafil, Apomormphine, Yohimbine, Tramadol, Dapoxetine, and Trazodone. It shed the light on mode of action and different analytical techniques used for their determination either alone or in combination with other drugs in different pharmaceutical and biological samples.

\section{References}

1. McKinlay JB (2000) The worldwide prevalence and epidemiology of erectile dysfunction. Int J Impotence Res 12: S6-S11.

2. Sweetman SC (2009) Martindale: the complete drug reference. Pharmaceutical Press, London: 3335.

3. Feldman HA, Goldstein I, Hatzichristou DG, Krane RJ, McKinlay JB (1994) Impotence and its medical and psychosocial correlates: results of the Massachusetts Male Aging Study. J Urol 151: 54-61.

4. Montague DK, Jarow JP, Broderick GA, Dmochowski RR, Heaton JP, et al. (2005) Chapter 1: The management of erectile dysfunction: an AUA update. J Urol 174: 230-239.

5. Lin JC. Douglass MA (2010) Erectile dysfunction and premature ejaculation: underlying causes and available treatments. Medical Economics.

6. Giuliano F. Hellstrom WJG (2008) The pharmacological treatment of premature ejaculation. BJU Int 102: 668-675.

7. Payne RE, Sadovsky R (2007) Identifying and treating premature ejaculation: importance of the sexual history. Cleve Clin J Med 74: S47-S53.

8. O'Neil MJ (2013) The Merck Index: An Encyclopedia of Chemicals, Drugs and Biologicals. Royal Society of Chemistry.

9. Issa YM, El-Hawary WF, Youssef AF, Senosy AR (2010) Spectrophotometric determination of sildenafil citrate in pure form and in pharmaceutical formulation using some chromotropic acid azo dyes. Spectrochim Acta A Mol Biomol Spectrosc 75: 1297-1303.

10. Harikrishna K, Nagaralli B, Seetharamappa J (2008) Extractive spectrophotometric determination of sildenafil citrate (viagra) in pure and pharmaceutical formulations. J Food Drug Anal 16.

11. Wang CC, Gómez RA, Fernandez LP (2013) Determination of sildenafil by preconcentration on surfactant coated polymeric resin followed by spectrofluorimetry. J Pharm Anal 3: 173-179.

12. Tyszczuk K, Korolczuk M (2010) Voltammetric method for the determination of sildenafil citrate (Viagra) in pure form and in pharmaceutical formulations. Bioelectrochemistry 78: 113-117.

13. Lović J, Trišović $\mathrm{N}$, Antanasijević J, Nikolić ND, Stevanović S, et al. (2016) Electrochemical determination of sildenafil citrate as standard, in tablets and spiked with human serum at gold and cystein modified gold electrode. J Electroanal Chem 782: 103-107.

14. Frag EYZ, Mohamed GG, Alelaiwi HMS (2011) Electroanalytical determination of sildenafil in Viagra tablets using screen-printed and conventional carbon paste electrodes. J Electroanalytic Chem 659: 121-127.

15. Wollein U, Schech B, Hardt J, Schramek N (2016) Determination and quantitation of sildenafil and its major metabolite in the breast milk of a lactating woman. J Pharm Biomed Anal 120: 100-105.
16. Mokhtar SU, Chin ST, Kee CL, Low MY, Drummer OH, et al. (2016) Rapid determination of sildenafil and its analogues in dietary supplements using gas chromatography-triple quadrupole mass spectrometry. J Pharm Biomed Anal 121: 188-196.

17. Al-Hroub H, Alkhawaja B, Alkhawaja E, Arafat $T$ (2016) Sensitive and rapid HPLC-UV method with back-extraction step for the determination of sildenafil in human plasma. J Chromatogr B Analyt Technol Biomed Life Sci 1009-1010: 1-6.

18. Aboul-Enein HY, Hefnawy MM (2003) Rapid determination of sildenafil citrate in pharmaceutical preparations using monolithic silica HPLC column. J Liq Chromatogr Relat Technol 26: 2897-2908.

19. Qin W, Li SFY (2002) An ionic liquid coating for determination of sildenafil and UK-103,320 in human serum by capillary zone electrophoresis-ion trap mass spectrometry. Electrophoresis 23: 4110-4116.

20. https://pubchem.ncbi.nlm.nih.gov

21. https://www.drugbank.ca

22. Kumar N, Sangeetha D, Kalyanraman L, Sainath K (2017) StabilityIndicating HPLC Method for Simultaneous Determination of Degradation Products and Process-Related Impurities of Avanafil in Avanafil Tablets. Acta Chromatographica: 1-6.

23. Fahmy UA, Aljaeid BM (2016) Stability indicating HPLC method for analysis of Avanafil using diode array detector 5: 1-6.

24. Mangukiya M, Patel G, Rathod B, Dhaduk D, Maniya J (2012) Development and Validation of Spectroscopic Methods for Simultaneous Estimation of Avanafil and Dapoxetine Hydrochloride in Combined Dosage Form. Inventi Rapid: Pharm Analysis Quality Assurance.

25. Chaudhari HH, Sen DJ, Patel C (2015) Development and Validation of HPTLC Method for Simultaneous Estimation of Avanafil and Dapoxetine $\mathrm{HCl}$ in Tablet Dosage Form. World J Pharm Sci 4: 15661575.

26. Hegazy M, Kessiba A, Abdelkawy M, El-Gindy AE (2015) RP-HPLC with Time Programmed Fluorescence Detection for Quantitation of Avanafil and Dapoxetine Hydrochloride: Application to Pharmaceutical Dosage Form and Biological Fluid. J Liquid Chromatograp Related Tech 38: 1660-1665.

27. Patel MN, Kothari CS (2016) Multivariate approaches for simultaneous determination of avanafil and dapoxetine by UV chemometrics and HPLC-QbD in binary mixtures and pharmaceutical product. J AOAC Int 99: 649-663.

28. Andersson KE (2011) Mechanisms of penile erection and basis for pharmacological treatment of erectile dysfunction. Pharmacol Rev 63: 811-859.

29. Van Tyle WK, Burkman AM (1971) Spectrofluorometric assay of apomorphine in brain tissue. J Pharm Sci 60: 1736-1738.

30. Eriksson BM, Persson BA, Lindberg M (1979) Determination of apomorphine in plasma and brain tissue by ion-pair extraction and liquid chromatography. J Chromatography A 185: 575-581.

31. Sam E, Augustijns P, Verbeke N (1994) Stability of apomorphine in plasma and its determination by high-performance liquid chromatography with electrochemical detection. J Chromatogr B Biomed Appl 658: 311-317.

32. Tan L, Chin SF, Miner VW, Dong L, Gupta S, et al. (2016) Determination of apomorphine freebase in sublingual tablets by proton nuclear magnetic resonance spectroscopy. J Pharm Biomed Anal 129: 378382.

Citation: Ibrahim AE, Elhenawee M, Saleh H, Sebaiy MM (2021) Erectile Dysfunction and Premature Ejaculation Drugs: Mode of Action and Analytical Methods Literature Review. J Drug Res Dev 7(1): dx.doi.org/10.16966/2470-1009.163 
33. Hashem H, Ibrahim AE, Elhenawee M (2014) Chromatographic analysis of some drugs employed in erectile dysfunction therapy: Qualitative and quantitative studies using calixarene stationary phase. J Sep Sci 37: 2814-2824.

34. Xu Y, Xu G (2005) Determination of apomorphine, sildenafil and alprostadil in medicines for erectile dysfunction by high performance liquid chromatography-mass spectrometry. Se Pu 23: 633-635.

35. Švorc L', Stanković D, Mehmeti E, Kalcher K (2014) Sensitive electrochemical determination of yohimbine in primary bark of natural aphrodisiacs using boron-doped diamond electrode. Analytical Methods 6: 4853-4859.

36. Farouk, M, Abd El-Aziz L, El-Gindy AE, Shokry E (2011) Validated methods for determination of yohimbine hydrochloride in the presence of its degradation products. Bull Faculty Pharm, Cairo University 49: 67-79.

37. Chiba R, Shinriki M, Ishii Y, Tanaka A (1998) High-performance liquid chromatographic determination of yohimbine in serum by chemiluminescence detection. Anal Sci 14: 975-978.

38. Betz JM, White KD (1995) Gas chromatographic determination of yohimbine in commercial yohimbe products. J AOAC Int 78: 11891194.

39. Zhang, Y, Huang Z, Ding L, Yan H, Wang M (2010) Simultaneous determination of yohimbine, sildenafil, vardenafil and tadalafil in dietary supplements using high-performance liquid chromatographytandem mass spectrometry. J Sep Sci 33: 2109-2114.

40. Kmetec V, Roškar R (2003) HPLC determination of tramadol in human breast milk. J Pharm Biomed Anal 32: 1061-1066.

41. Curticapean A, Muntean D, Curticapean M, Dogaru M, Vari C (2008) Optimized HPLC method for tramadol and O-desmethyl tramadol determination in human plasma. J biochem biophys meth 70: 13041312 .

42. Becker R, Lintz W (1986) Determination of tramadol in human serum by capillary gas chromatography with nitrogen-selective detection. J Chromatogr 377: 213-220.

43. Sheibani A, Haghpazir N (2014) Application of ion mobility spectrometry for the determination of tramadol in biological samples. J Food Drug Anal 22: 500-504.

44. Abdellatef HE (2002) Kinetic spectrophotometric determination of tramadol hydrochloride in pharmaceutical formulation. J Pharm Biomed Anal 29: 835-842

45. Garrido E, Garrido J, Borges, F, Delerue-Matos C (2003) Development of electrochemical methods for determination of tramadolanalytical application to pharmaceutical dosage forms. J Pharm Biomed Anal 32: 975-981.

46. Deiminiat B, Rounaghi GH, Arbab-Zavar MH (2017) Development of a new electrochemical imprinted sensor based on poly-pyrrole, solgel and multiwall carbon nanotubes for determination of tramadol. Sens Actuators B Chem 238: 651-659.

47. Tambe VS, Deodhar MN, Prakya V (2016) LC and LC-MS study for simultaneous determination of tramadol hydrochloride and ketorolac tromethamine in bulk and formulation with their major degradation products. Bull Faculty Pharm, Cairo University 54: 8797.

48. Glavanović S, Glavanović M, Tomišić V (2016) Simultaneous quantitative determination of paracetamol and tramadol in tablet formulation using UV spectrophotometry and chemometric methods. Spectrochim Acta A Mol Biomol Spectrosc 157: 258-264.
49. Chitravathi S, Munichandraiah N (2016) Voltammetric determination of paracetamol, tramadol and caffeine using poly(Nile blue) modified glassy carbon electrode. J Electroanal Chem 764: 93-103.

50. Fathy WM, Farag RS, El Nawawy M, Atiaa H, Mahdy T (2013) High Performance Liquid Chromatography Method to Detect Tramado and Sildenafil in the Blood of Rats on Combination Treatment. Int J Computers Tech: 2682-2690.

51. Vineeta KV, Muralikrishna K (2013) Development and Validation of UV Spectrophotometric method for estimation of Dapoxetine $\mathrm{HCL}$ in bulk and dosage Form. Int J Drug Dev Res 5: 1-7.

52. Aziz A, Khamees N, Mohamed TA, Derar AR (2016) Comparative Study of PVC-Free All-Solid-State, PVC Membrane, and Carbon Paste Ion-Selective Electrodes for the Determination of Dapoxetine Hydrochloride in Pharmaceutical Formulation. J AOAC Int 99: 14991504.

53. Kim TK, Kim IS, Hong SH, Choi YK, Kim H, et al. (2013) Determination of dapoxetine in rat plasma by ultra-performance liquid chromatography-tandem mass spectrometry. J Chromatogr B Analyt Technol Biomed Life Sci 926: 42-46.

54. Abdel-Moety MM, Souaya ER, Soliman EA (2015) Spectrophotometric methods for simultaneous determination of vardenafil and dapoxetine hydrochlorides in combined dosage form. World Pharm Pharm Sci 4: 120-133.

55. Attia AK, Souaya ER, Soliman EA (2015) Thermal analysis investigation of dapoxetine and vardenafil hydrochlorides using molecular orbital calculations. Advanced Pharmaceutical Bulletin 5: 523-529.

56. Savjiyani NB, Patel P (2013) Simultaneous estimation of vardenafil hydrochloride and dapoxetine hydrochloride in combined pharmaceutical dosage form by spectrophotometry and RP-HPLC. Indo Am J Pharm Res 3: 3652-3668.

57. Rajeshwari M, Chenthilnathan A, Rama K (2014) Validated RP-HPLC method for simultaneous estimation of tadalafil and dapoxetine hydrochloride in combined pharmaceutical dosage forms. Int J Pharm Biol Sci 4: 72-82.

58. Giri AD, Bhusari VK, Dhaneshwar SR (2012) Validated HPLC method for simultaneous quantitation of tadalafil and dapoxetine hydrochloride in bulk drug and formulation. Int J Pharm Pharm Sci 4: 654-658.

59. Hegazy M, Kessiba A, Abdelkawy M, El-Gindy AE (2015) A novel liquid chromatographic method with fluorescence detection for quantitation of tadalafil and dapoxetine hydrochloride in pharmaceutical dosage form and human plasma. Chinese J. Chromatogr 33: 765-770.

60. Prajapati CA, Patel BS (2014) Development and validation of spectrophotometric method for simultaneous determination of sildenafil citrate and dapoxetine hydrochloride in their combined dosage formulation. PharmaTutor 2: 84-88.

61. Prajapati CA, Patel B, Badmanaban R (2014) Development and Validation of HPTLC Method for Simultaneous Estimation of Sildenafil Citrate and Dapoxetine Hydrochloride in Combined Dosage Form. PharmaTutor 2: 142-152.

62. Haribabu Y, Eapen SC, Kutty S, Kumar P (2013) Validated RP-HPLC Method for Simultaneous Estimation of Sildenafil Citrate and Dapoxetine $\mathrm{HCl}$ in Tablet Dosage Form. Pharma Innovat J 2: 40-45.

63. Dhaduk D, Jadeja B, Patel H, Rathod B, Patel (2012) Estimation of sildenafil citrate and dapoxetine hydrochloride in their combined dosage form by validated HPLC method. Inventi Rapid: Pharm Analysis \& Quality Assurance. 
64. Fink HA, MacDonald R, Rutks IR, Wilt TJ (2003) Trazodone for erectile dysfunction: A systematic review and meta-analysis. BJU Int 92: 441-446.

65. Sullivan G (1988) Increased libido in three men treated with trazodone. J Clin Psychiatry 49: 202-203.

66. Gartrell N (1986) Increased libido in women receiving trazodone. Am J Psychiatry 143: 81-82.

67. Khalil S (1999) Ion-selective electrode for the determination of trazodone in tablets. Analyst 124: 139-142.
68. Hegde RN, Shetti NP, Nandibewoor ST (2009) Electro-oxidation and determination of trazodone at multi-walled carbon nanotubemodified glassy carbon electrode. Talanta 79: 361-368.

69. El-Gindy A, El-Zeany B, Awad T, Shabana MM (2001) Spectrophotometric, spectrofluorimetric and LC determination of trazodone hydrochloride. J Pharm Biomed Anal 26: 211-217.

70. Dogrukol-Ak D, Zaimoglu V, Tunçel M (1999) Voltammetry of trazodone by platinum electrode and its determination in tablets using DP technique in the rotating conditions. Eur J Pharm Sci 7: 215-220. 